NASA Contractor Report 198368

\title{
Numerical Simulation of Supersonic Flow Using a New Analytical Bleed Boundary Condition
}

G.J. Harloff and G.E. Smith NYMA, Inc.

Brook Park, Ohio

August 1995

Prepared for

Lewis Research Center

Under Contract NAS3-27186

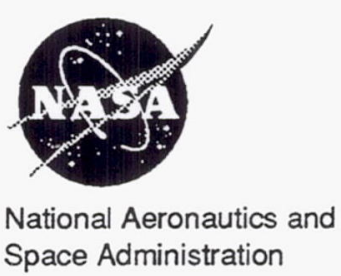


Trade names or manufacturers' names are used in this report for identification only. This usage does not constitute an official endorsement, either expressed or implied, by the National Aeronautics and Space Administration. 


\title{
NUMERICAL SIMULATION OF SUPERSONIC FLOW USING A NEW ANALYTICAL BLEED BOUNDARY CONDITION
}

\author{
G.J. Harloff* \\ G.E. Smith** \\ NYMA, Inc. \\ NASA Lewis Research Center \\ Brook Park, Ohio 44142
}

\begin{abstract}
A new analytical bleed boundary condition is used to compute flowfields for a strong oblique shock wave/boundary layer interaction with a baseline and three bleed rates at a freestream Mach number of 2.47 with an $8 \mathrm{deg}$ shock generator. The computational results are compared to experimental Pitot pressure profiles and wall static pressures through the interaction region. An algebraic turbulence model is employed for the bleed and baseline cases, and a one equation model is also used for the baseline case where the boundary layer is separated.
\end{abstract}

\section{Nomenclature}

$\begin{array}{cl}H_{i} & \text { incompressible shape factor, } \delta_{i}^{*} / \theta_{i} \\ u_{e} & \text { boundary layer edge velocity } \\ \delta & \text { boundary layer thickness } \\ \delta_{i}^{*} & \text { displacement thickness, } \int_{\delta}^{\delta}\left(1-\frac{u}{u_{e}}\right) d y \\ \theta_{i} & \text { momemtum thickness, } \int_{o}^{\delta} \frac{u}{u_{c}}\left(1-\frac{u}{u_{e}}\right) d y\end{array}$

\section{Introduction}

The boundary layer flow in supersonic inlets is typically bled off to avoid adverse shock-boundarylayer interactions and subsequent total pressure losses in the subsonic diffuser. Currently, bleed flow rates are determined from empirical flow coefficients which are measured in wind tunnels for various Mach numbers, boundary layer profiles, and bleed plates. These coefficients are dependent on local Mach number, pressure ratio, hole or slot geometry, and bleed hole length to diameter ratio, (L/D), etc. Because

\footnotetext{
* Senior engineer II, Associate Fellow ALAA

** Research Engineer, Senior Member AIAA

Copyright (C) by Harloff and Smith. Published by the

American Institute of Aeronautics and Astronautics with permission.
}

of scale effects, these data may not be readily scalable to full scale. It is the purpose of this paper to use a newly developed analytical bleed model boundary condition and compare CFD predictions to experimental data representative of shock wave/boundary layer interactions with boundary layer bleed in supersonic inlets.

\section{New Bleed Modeling Approach}

The new anaytic bleed model is based on conservation of mass, momentum and energy for flow through a single hole or slot and empirical relations. The approach permits the local sonic flow coefficient to vary with local flow conditions, hole or slot geometry, and orientation. In this paper the bleed holes are 90 deg with short L/D. The bleed duct is modeled like a pitot inlet with a detached normal shock when the boundary layer edge is supersonic. The flowfield is examined during the solution process to provide the surface static pressure and edge total conditions. The specified plenum pressure is then used to calculate the pressure drop across the bleed plate. The model along with a specified porosity provides the momentum flux through the computational bleed surface. The analytical bleed model has been coded as a boundary condition to compute the bleed momentum as a function of the local flowfield and plenum pressure. When the local wall pressure is less than the plenum pressure, outflow is computed as will be discussed below. The new boundary condition is similar to using a table look-up for the sonic flow coefficient and has the added feature that continuous edge Mach numbers and plenum pressure ratioes can be used. The analytical model has predicted flow coefficients for 90,40 , or 20 degree holes or narrow slots and is designed for arbitrary angles, and is fully described by Harloff and Smith ${ }^{1}$. 


\section{Numerical CFD Code}

The NPARC 2 2-D version $1.1 \mathrm{~b}$ code was used to compute the flowfield and was modified for the new bleed boundary condition. The code solves the full Navier-Stokes equations in strong conservation form. Closure was obtained by applying the Baldwin-Lomax ${ }^{3}$ turbulence model, which was not modified (in this paper) to account for bleed for the cases considered. In addition, the Baldwin-Barth ${ }^{4}$ turbulence model was employed in NPARC 2-D version 2.0 for the baseline no holes case. The grid was generated using $I 3 G^{5}$ and hyperbolic stretching was used at the walls and in the axial direction. A schematic of the test configuration is shown in Fig. 1. The shock generator angle was $8 \mathrm{deg}$ and the inviscid oblique shock impingement point was set to impinge on the middle of the bleed plate. The grid density was 300 in the $\mathrm{X}$ direction and 200 in the $\mathrm{Y}$ direction and 150 axial points in the bleed region, see Fig. 2. In the boundary layer flow in front of the bleed region the $\mathrm{y}+$ for the first grid point from the walls was about 2. The upstream boundary layer and freestream conditions were specified at the inflow boundary, no slip was assumed on the shock generator and the wind tunnel walls, slip was assumed on the upper boundary in front of and behind the shock generator, and the new analytical boundary condition was applied along the entire lower wall. For the baseline no holes case, the no slip boundary condition was applied in the "bleed" region. The plenum to freestream total pressure ratios specified include: $0.12,0.10$, and .001 for zero, half choked, and choked bleed respectively.

\section{Comparison with Test Data}

The test data of Willis, Davis, and Hingst ${ }^{6}$ has been modeled. CFD predictions are compared to experimental data for Mach 2.47 freestream with an 8 degree shock generator angle for no holes baseline, holes with zero net bleed, half choked, and choked bleed holes. "Choked bleed holes" refers to sonic flow condition within the holes with maximum flow rate. Half choked refers to half the choked mass flow rate. The bleed region contains 8 rows of holes of $0.635 \mathrm{~cm}(0.25 \mathrm{in})$ diameter. The hole spacing longitudinally and laterally between centers is 2 diameters. The total bleed area is $31.67 \mathrm{~cm}^{2}\left(4.9087 \mathrm{in}^{2}\right)$ with 100 holes and the bleed area is $9.525 \mathrm{~cm}(3.75$ in) long by $15.875 \mathrm{~cm}(6.25 \mathrm{in})$ wide for a porosity is 0.208 . Aerodynamic fences were positioned, in the flow direction, $8.89 \mathrm{~cm}$ ( $3.5 \mathrm{in})$ from the bleed plate centerline to help insure 2-dimensionality of the flow. The bleed region axial location is $0.0 \mathrm{~cm}$ and length is $9.52 \mathrm{~cm}(3.75 \mathrm{in})$.

\section{Static Pressure}

The wall static pressures for the 4 cases considered are compared with experimental data in Fig. 3. As indicated by the data, the pressure rise for this shock wave/boundary layer interaction is stong enough to separate the boundary layer for the no bleed hole baseline case (open circles). The CFD predicted pressure rise is about the same as the experimental values downstream of $4 \mathrm{~cm}$. However, upstream of this point the experimental data indicates the presence of much larger separated boundary layer flow region than predicted by CFD. This result is expected as the algebraic Baldwin-Lomax turbulence model usually predicts boundary layer separation late. The experimental pressure rise starting at $20 \mathrm{~cm}$ is thought to be due to shock waves from the leading edge of the fences. The CFD predicted pressure drop at $28 \mathrm{~cm}$ is probably due to the expansion from the upper boundary condition change at the end of the shock generator, i.e. from no slip to slip. The one equation Baldwin-Barth turbulence model was employed to determine if it is better able to predict the separated boundary layer flow. With this model the predicted boundary layer separation moved only slightly upstream by about $0.7 \mathrm{~cm}$ compared to the Baldwin-Lomax turbulence model; both models underpredict the extent of the separated boundary layer. Both models predict similar wall static pressure levels further downstream. The Baldwin-Lomax model was used for all of the other cases. For the zero bleed case (solid circles), with the bleed plate installed and zero net bleed, the experimental boundary layer separation moved forward of the no hole baseline case, and the downstream (of the bleed plate) pressure plateau is lower than the baseline case. For the half-choked case, the test data (open squares) indicates that the boundary layer separation moved downstream compared to the baseline case as expected. The CFD half-choked predictions are coincident with the CFD zero bleed up to about $4 \mathrm{~cm}$. The pressure difference across the bleed plate is not large enough, upstream of the oblique shock impingement, to bleed much of the boundary layer. The wall static pressures indicate that the bleed flow is recirculating and blowing for the zero bleed case, e.g. higher pressures in front of the shock impingement and lower pressures behind it compared to the no hole baseline case. For 
the choked case, the CFD pressure rise curve agrees closely with the experimental data; however, the predictions underpredict the maximum pressure on the aft portion of the bleed plate. In the computation the bleed is removed through a continuous porous surface whereas the pressure measurements are made on solid surfaces and it is not clear that the (porous) CFD values are directly comparable to experimental values on the bleed plate.

\section{Boundary Layer Shape Factor}

The CFD computed boundary layer incompressible shape factors, $H_{i}$ at the 14 rake locations for each of the 5 case are illustrated in Fig. 4. Values around 1.28 indicate a health fully developed turbulent boundary layer profile with a $1 / 7$ power law velocity profile. The upstream $H_{i}$ values for all the bleed cases is about 1.28 with the BaldwinLomax turbulence model; for the baseline case with the Baldwin-Barth turbulence model $H_{i}$ is lower at 1.26. The rapid rise in $H_{i}$ is similar for all cases, except the choked bleed case, to about 2.2 at $3 . \mathrm{cm}$ from the bleed region leading edge. Thereafter, $H_{i}$ decrease rapidly with increasing distance and at 23 $\mathrm{cm}$ the shape factors are about 1.43 for all the cases, except the choked bleed case which has a shape factor of 1.33. The peak $H_{i}$ for the choked bleed is 1.58. Thus, from the $H_{i}$ analysis, all the cases computed, except the choked bleed case, indicate separated boundary layer in the shock wave/boundary layer interaction region.

\section{Pitot Pressures}

Fourteen rakes were used in the experiment; the rake locations are: $-9.8,-8.2,-4.7,-2.2,0.4,2.9,5.5$, $8.0,11.513 .1,15.6,18.2,20.7 \mathrm{~cm}$ respectively. The CFD and experimental Pitot pressure profiles are compared in Figs. 5-9 for the baseline-no holes, zero bleed, half choked bleled and choked bleed cases respectively. The vertical dashed lines in the Pitot figures are the inviscid levels which vary depending if the rakes are upstream, between the incident and reflected, or downstream of the reflected shock. The test data and CFD Pitot values are normalized between zero and the inviscid values at each rake location. As expected good agreement betweed the CFD and experimental Pitot pressure profiles, for rakes 1 to 3 , is observed upstream of the shock-boundayer layer interaction for the baseline case shown in Fig. 5 and for all the other cases. The sharp discontinuity in Pitot pressure at about $-2 \mathrm{~cm}$ is where the inviscid oblique shock crosses rake no. 4. The experimental data indicates boundary layer separation at rakes 5-11 whereas the CFD does not. Consequently, downstream of the interaction, at rake 15 , the CFD overpredicts the Pitot pressures and underpredicts the boundary layer thickness. The Baldwin-Barth turbulence model was employed to evaluate its capability in this type of flowfield, see Fig. 6. The details are different, but the behavior is similar to the Baldwin-Lomax model. Both turbulence models underpredicted the vertical extent of the boundary layer flow separation. In addition to the no holes baseline case, a zero bleed case was also investigated. The bleed plenum pressure/freestream total pressure was specified and the model then determined local bleed from the local flowfield. Comparing the baseline pitot pressure profiles, Fig. 5 , with the no bleed case, Fig. 7 , shows that experimental pitot profiles differ for rakes 5 to 8 . The CFD profiles of Fig. 5 and 7 are similar to each other. When the bleed flow was increased to half choked, the experimental data indicates that the boundary layer separation was still present, see Fig. 8. The the CFD Pitot pressure predictions are qualitatively similar to the baseline case discussed above. The experimental Pitot pressures shown in Fig. 9 for the choked bleed case do not indicate boundary layer separtation and the CFD predictions are in better agreement with the test data for rakes $12-14$ than the previous comparisons.

\section{Mach Number Contours}

The computed Mach number contours in the shock wave/boundary layer interaction region are illustrated in Figs. 10-14. The shock from the shock generator is captured quite well as the upstream grid is aligned with the shock. The Mach number contour for the no hole baseline case is presented in Fig. 10. At the oblique shock impingement point the upstream boundary layer thickens as indicated by the rapid growth in the subsonic layer. A small region of reverse flow is underneath the shock reflection point. The Mach number contours for the Baldwin-Barth turbulence model is shown in Fig. 11 where the main difference is the slight forward propagation of the foot of the reflected oblique shock and a slightly larger separation area behind the foot of the reflected shock wave. For the zero bleed case the plenum pressure was set to 0.12 of freestream total pressure and flow was allowed to flow in or out of the bleed plenum depending on the local pressure gradient across the bleed plate. The velocity vectors shown in Fig. 12, which are greatly exager- 
ated with a scale factor of 128 compared to 8 for the choked bleed shown below, indicate that both inflow and outflow occur towards the rear of the bleed zone where the pressure is higher due to the pressure jump across the incident oblique shock. The maximum Mach number of the flow at the bleed plate for the zero bleed case is 0.0068 . The flow adjacent to the bleed plate appears to be slightly unsteady. This is not expected for flow within a separated boundary layer. A small amount of reverse flow is also predicted to occur for the half choke case when the plenum pressure decreases to 0.1 of freestream total pressure, see Fig. 13. The bleed velocity vectors are not uniform for this case. The vector scale used in Fig. 13 is 32 for the half choked case. When the bleed flow is choked, the velocity vectors in the forward part of the bleed zone are uniform as the density is uniform (the bleed boundary condition is cast in terms of momentum), see Fig. 14. Downstream of the reflected oblique shock the density increases and the velocity decreases in proportion to the density increase. Note that the vector scale for this bleed rate is 8 when comparing the vectors with thoses of the other bleed rates. Both the half and full choke cases indicate that an oblique shock forms at the end of the bleed plate due to change in the flow direction at this point. Similarly, the choked bleed case illustrates the flow expansion at the leading edge of the bleed region due to the boundary layer flow being turned into the bleed plate.

\section{Conclusions}

An analytical model for boundary layer bleed holes and slots has been implemented into a CFD code. The CFD wall static predictions indicate reasonably good agreement with experiment downstream of the interaction and indicate an underpridiction in the separated boundary layer for the lower bleed rates considered. The CFD Pitot pressures compare favorably with test data upstream of the bleed region and reasonably well downstream of the interaction. Further studies are needed to improve the capability of turbulence models in the regions of shock wave boundary layer interaciton with boundary layer separation. Additional studies are also needed to test the new analytical boundary condition in flows without boundary layer separation.

\section{Acknowledgements}

This work was supported by the NASA Lewis Research Center under contract NAS3-27186. The support provided by NASA contract monitors, Robert
E. Coltrin and Thomas J. Biesadny is appreciated. Many useful discussions were held with Dr. David Davis of NASA Lewis and James Sirbaugh of Nyma Inc. The computations were perfomed on the NAS Cray Y-MP at NASA Ames. The assistance of Tammy Langhals and Maryann Johnston is gratefully acknowledged.

\section{References}

1. Harloff, G.J. and Smith, G.E., "On Supersonic Inlet Boundary-Layer-Bleed Flows," AIAA Paper 95-0038, January 1995.

2. Cooper, G.K. and Sirbaugh, J.R., "The PARC Distinction: A Practical Flow Solver," AIAA paper 90-2002, July 1990 .

3. Baldwin, B.S. and Lomax, H., "Thin Layer Approximation and Algebraic Model for Separated Turbulent Flows," AIAA paper 78-257, 1978.

4. Baldwin, B.S. and Barth, T. J., "A OneEquation Turbulence Transport Model for High Reynolds Number Wall-Bounded Flows", NASA TM-102847.

5. "I3G/VIRGO: Interactive Graphics for Geometry Definition/Visual Interactive Rapid Grid Generation, User's Manual," Wright Patterson AFB, January 1990.

6. Willis, B., Davis, D., and Hingst, W., "Flowfield Measurements in a Normal-Hole-Bled Oblique Shock Wave and Turbulent Boundary Layer Interaction," AIAA Paper 95-2885, July, 1995. 


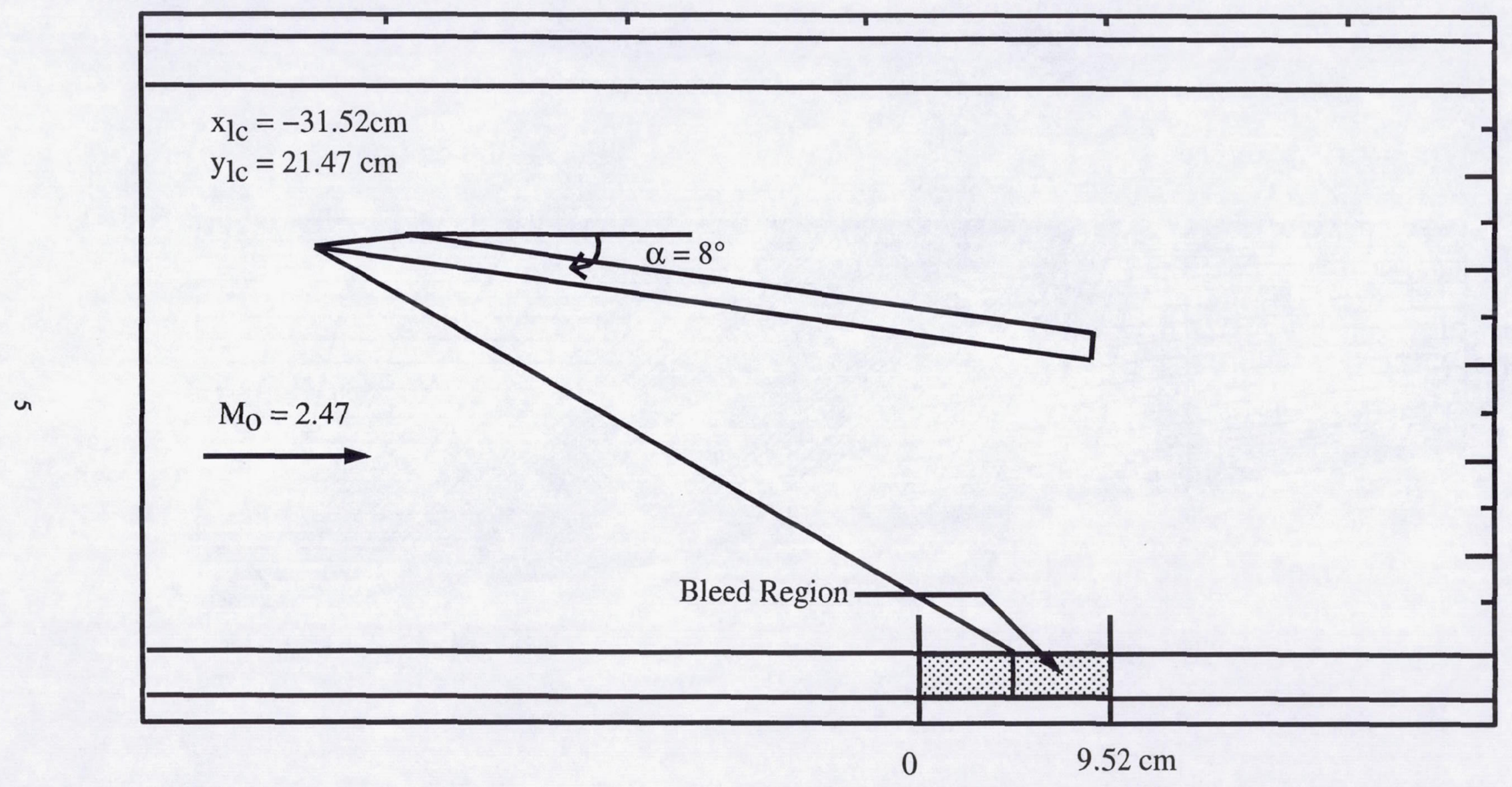

Fig. 1 - Geometry. 


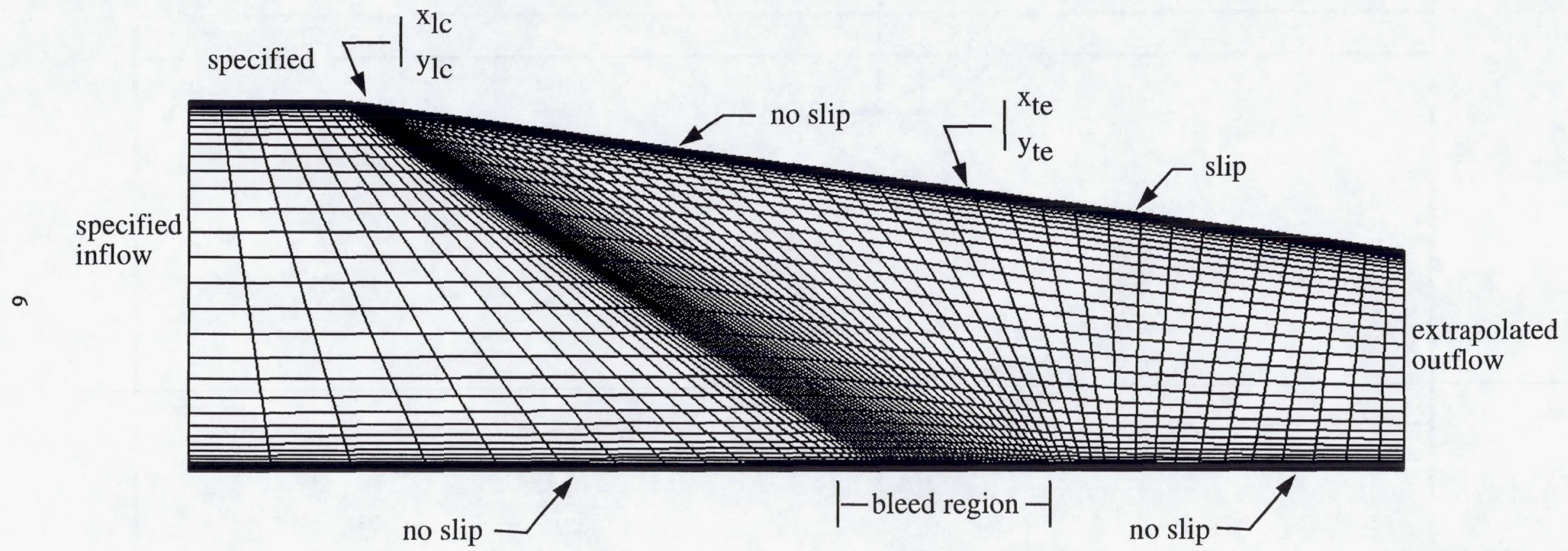

Fig. 2 - Grid and boundary conditions. 


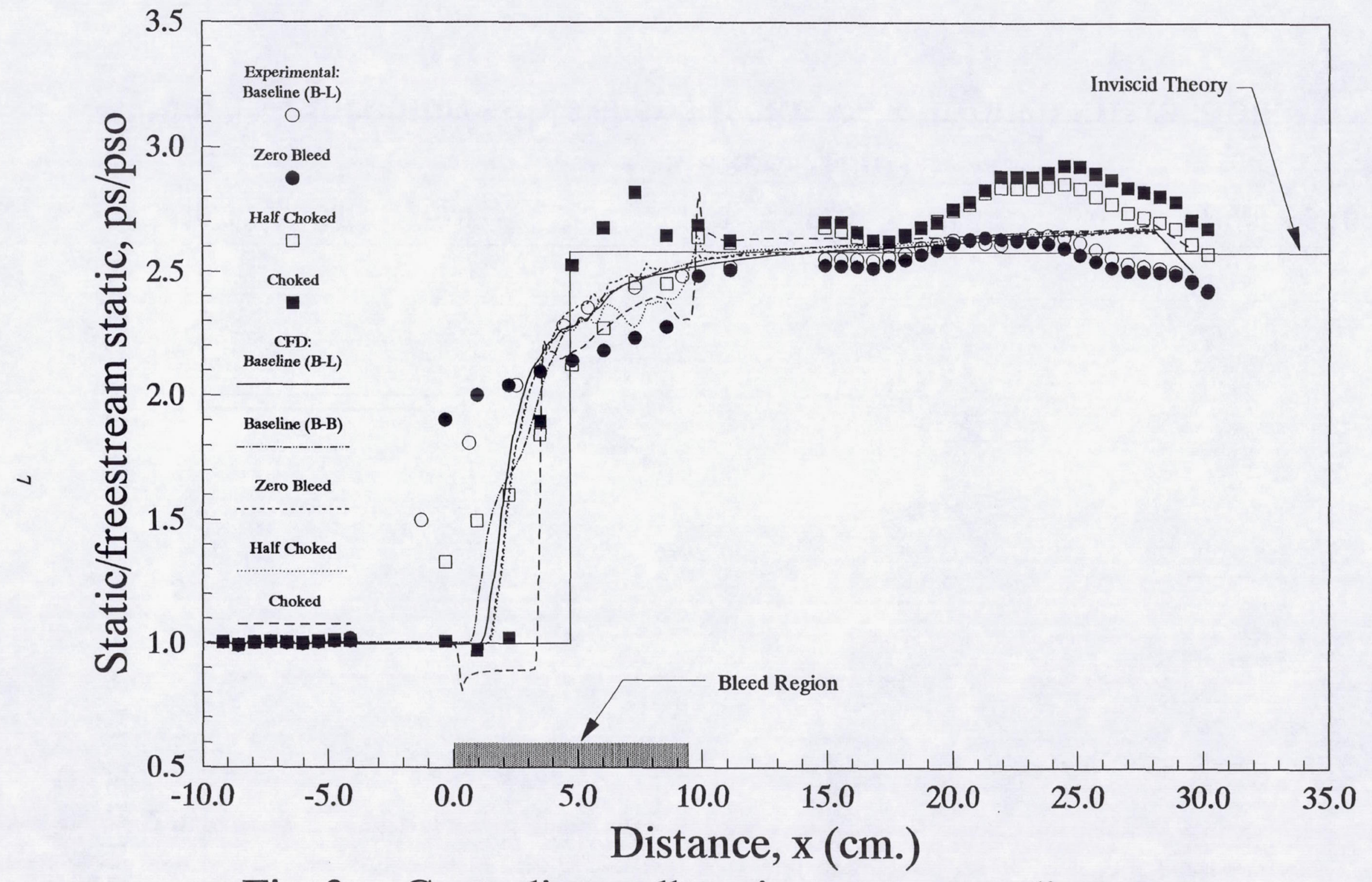

Fig. 3 - Centerline wall static pressure vs. distance. 


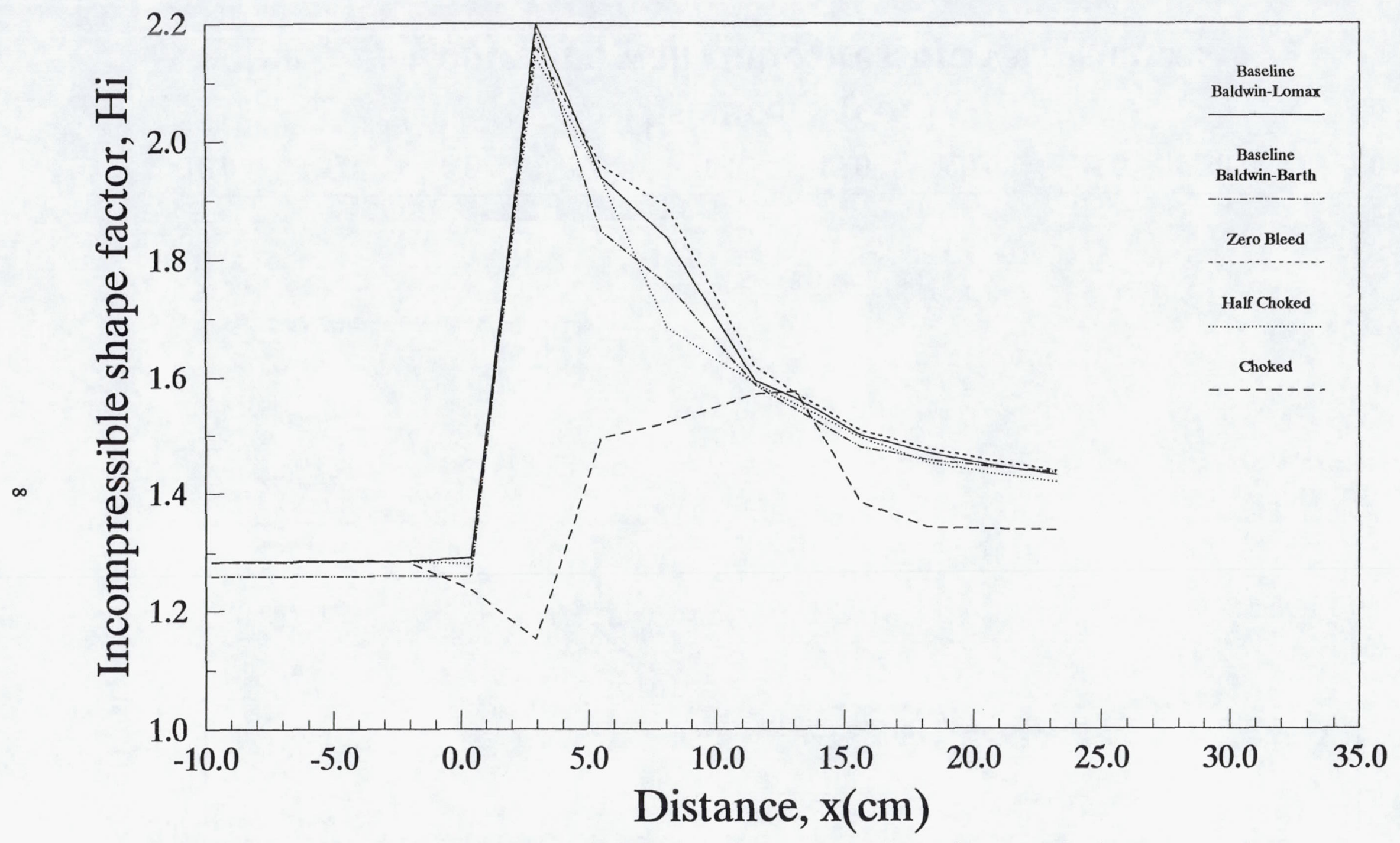

Fig. 4 - Incompressible shape factor vs. $\mathrm{x}$ through interaction. 


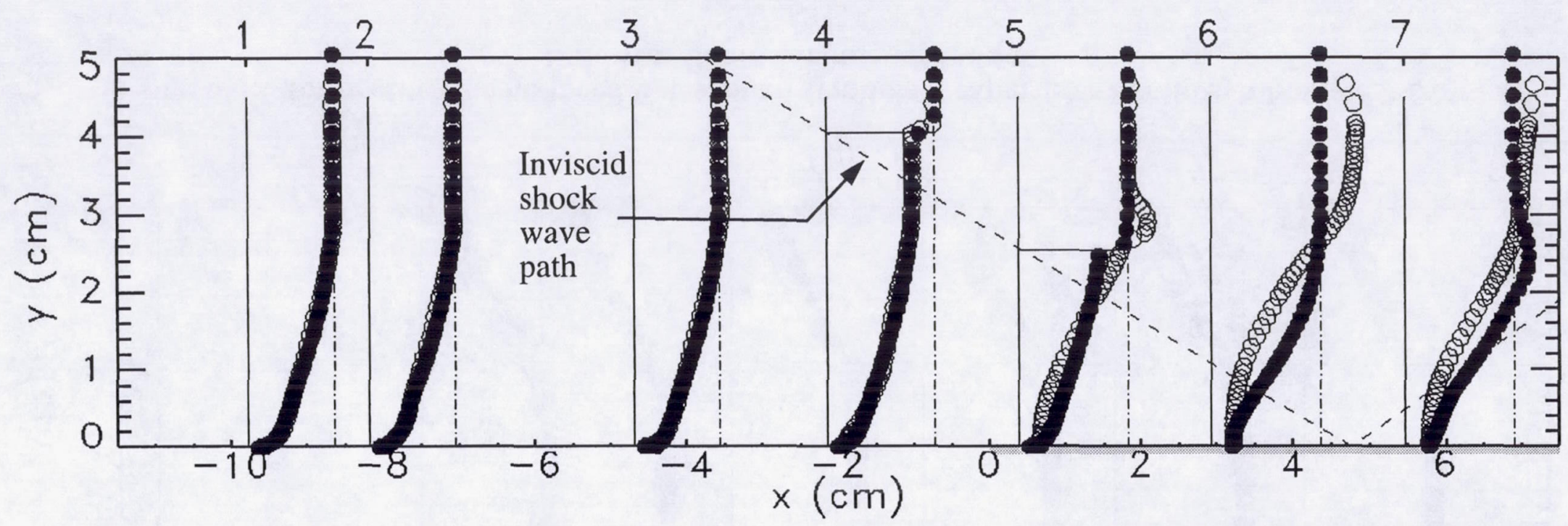

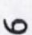

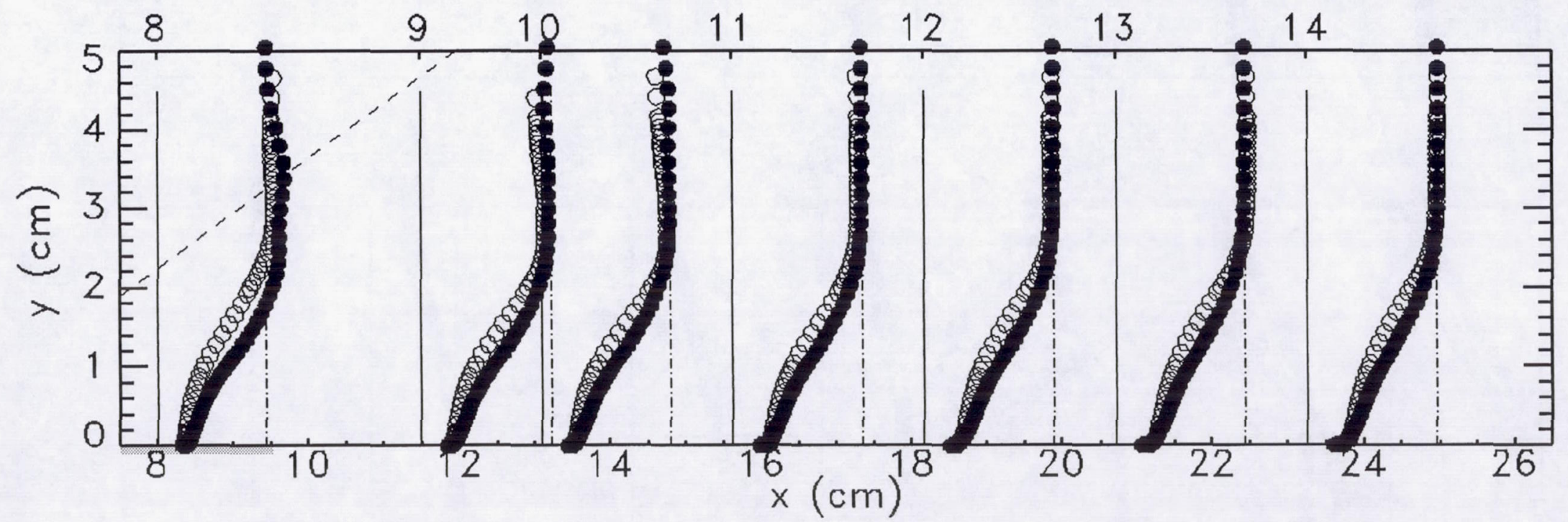

Fig. 5 - Pitot profiles for no bleed holes, open symbols - experiment, solid symbols - CFD, Baldwin-Lomax turbulence model. 


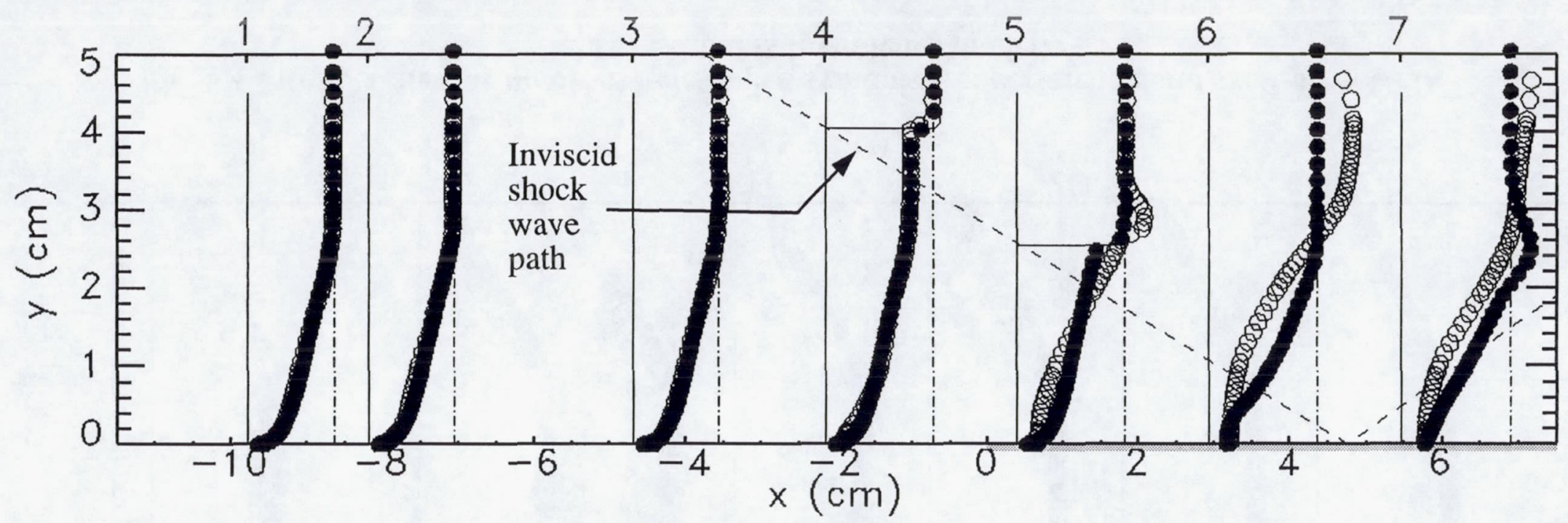

เ

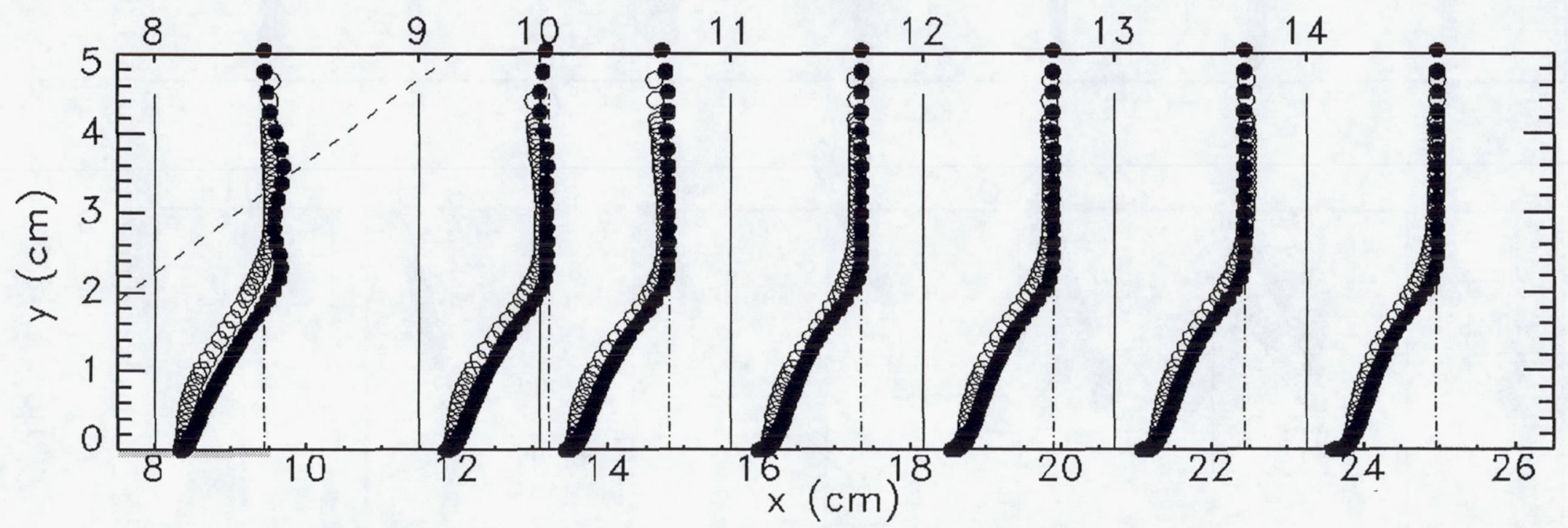

Fig. 6 - Pitot profiles for no bleed holes, open symbols - experiment, solid symbols - CFD, Baldwin-Barth turbulence model. 

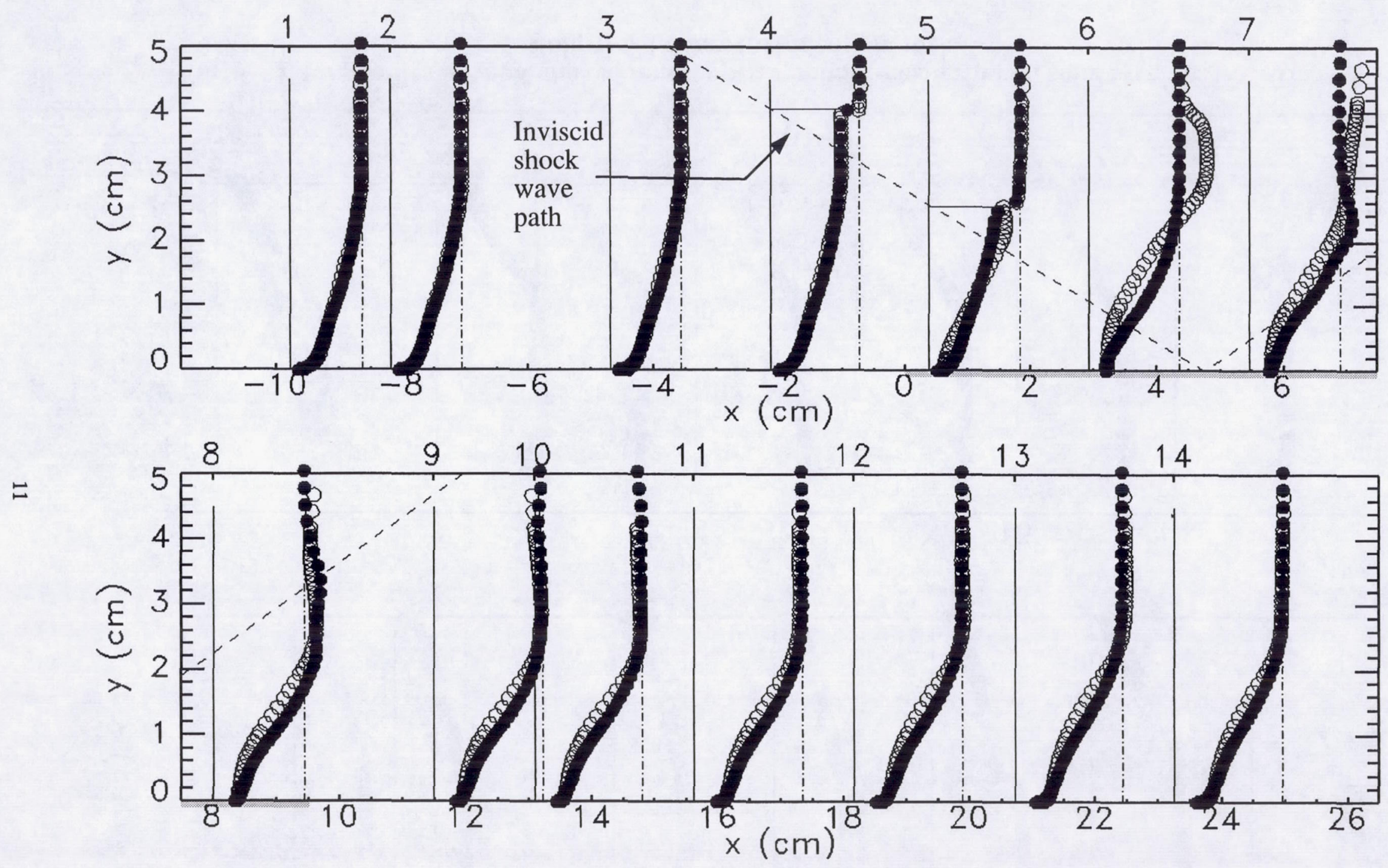

Fig. 7 - Pitot profiles for holes zero bleed, open symbols - experiment, solid symbols - CFD, Baldwin-Lomax turbulence model. 


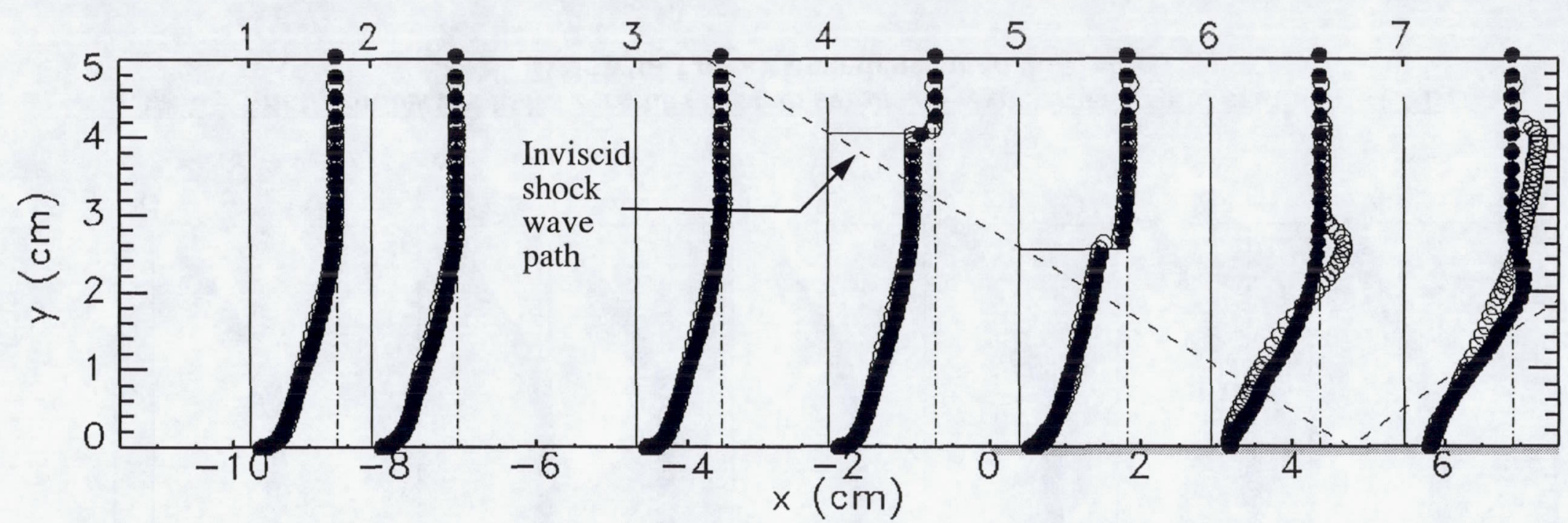

$\bar{N}$

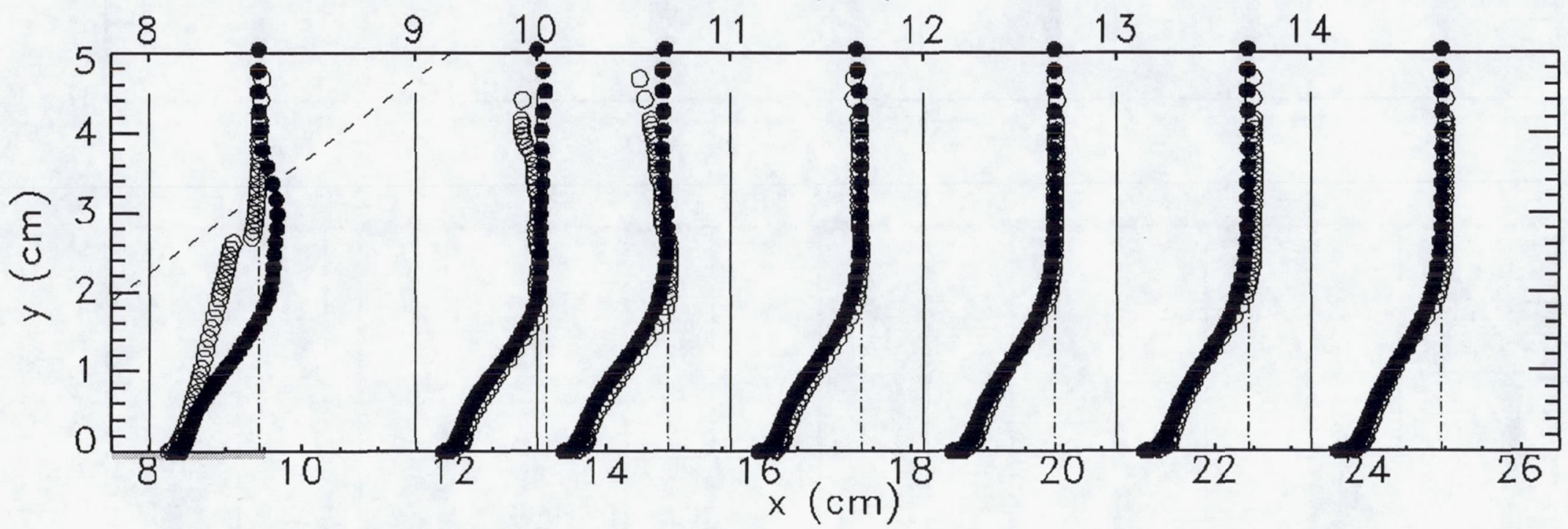

Fig. 8 - Pitot profiles for half choked holes, open symbols - experiment, solid symbols - CFD, Baldwin-Lomax turbulence model. 


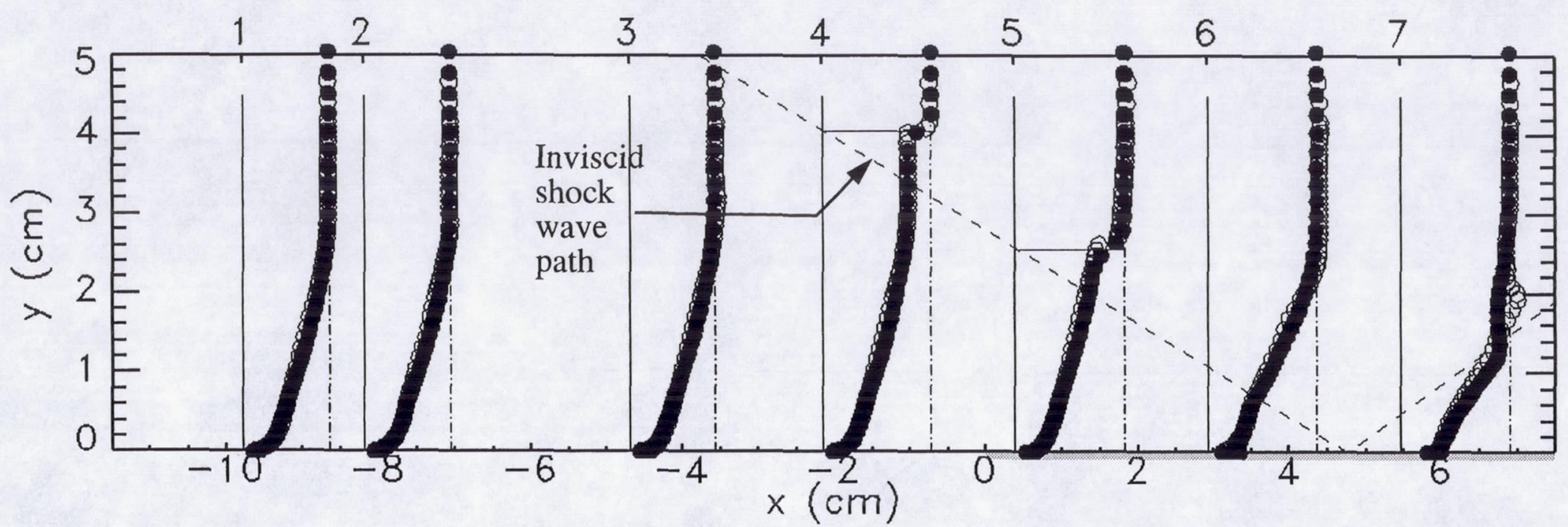

$\bar{\omega}$

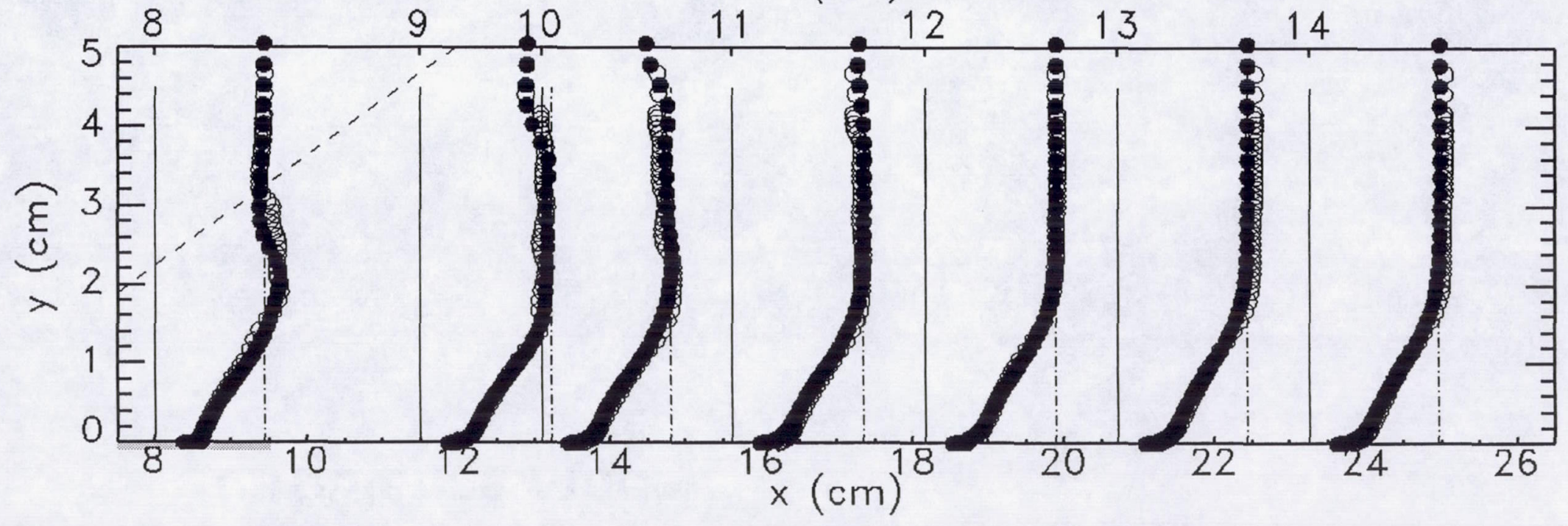

Fig. 9 - Pitot profiles for choked holes, open symbols - experiment, solid symbols - CFD, Baldwin-Lomax turbulence model. 

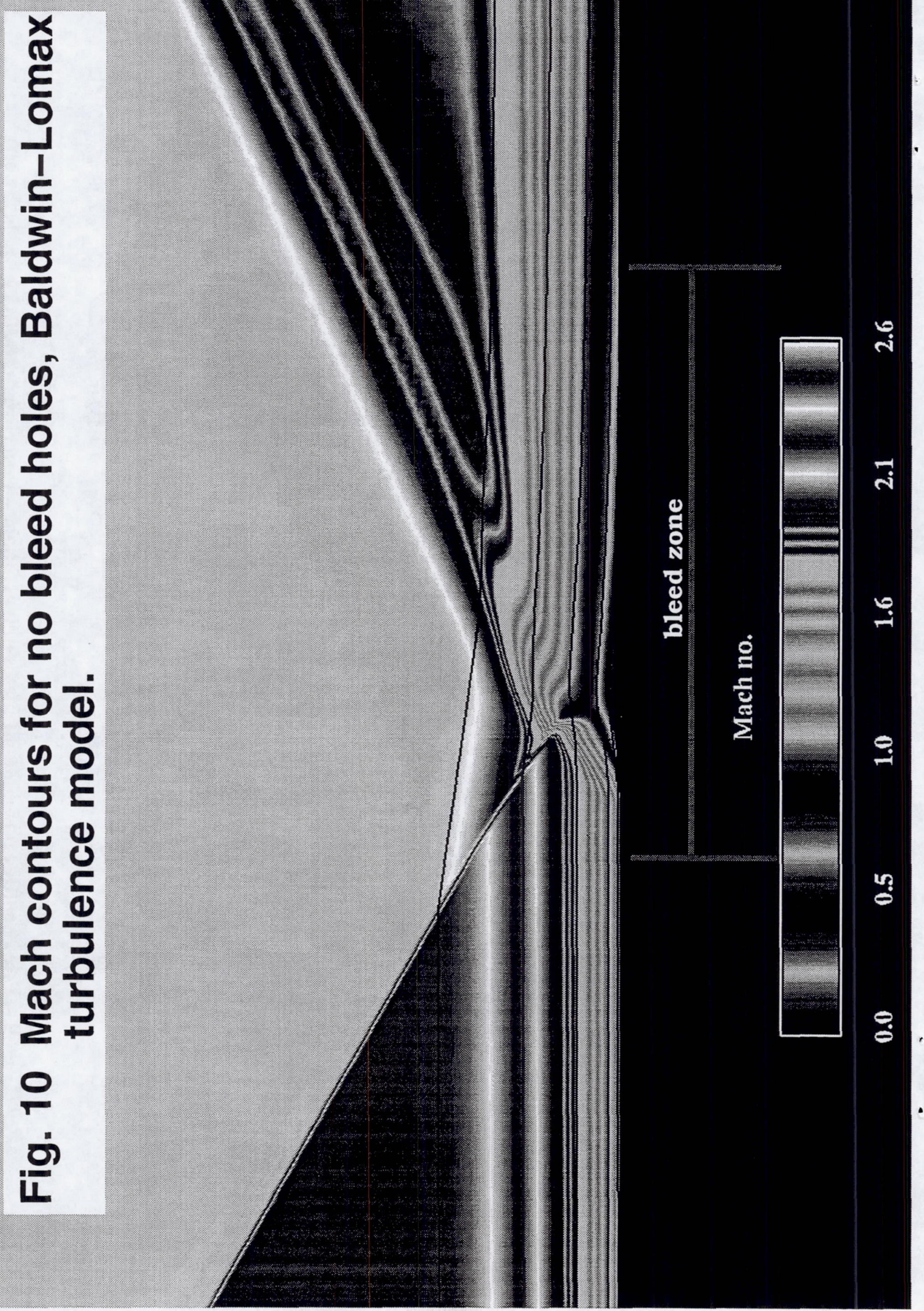

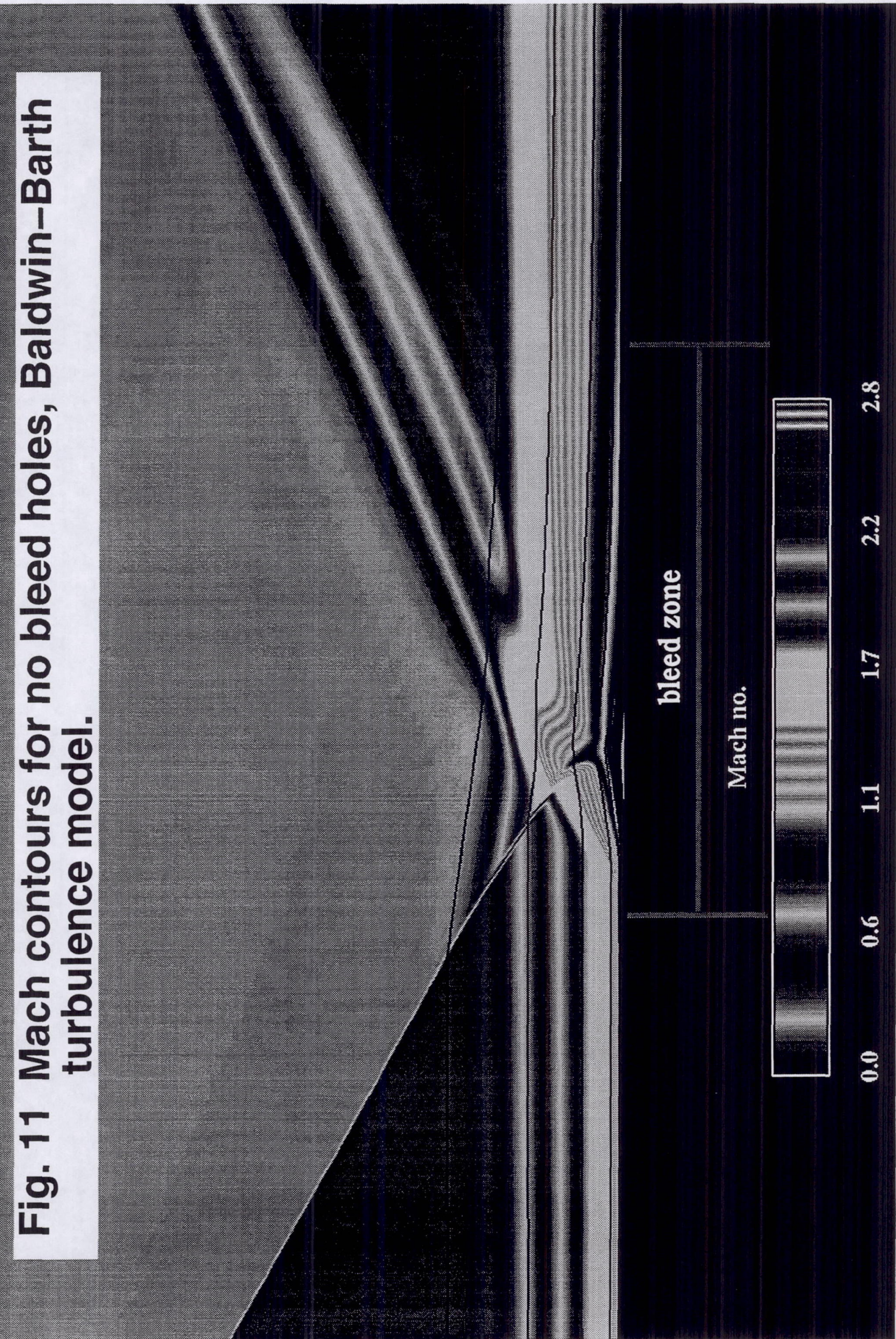


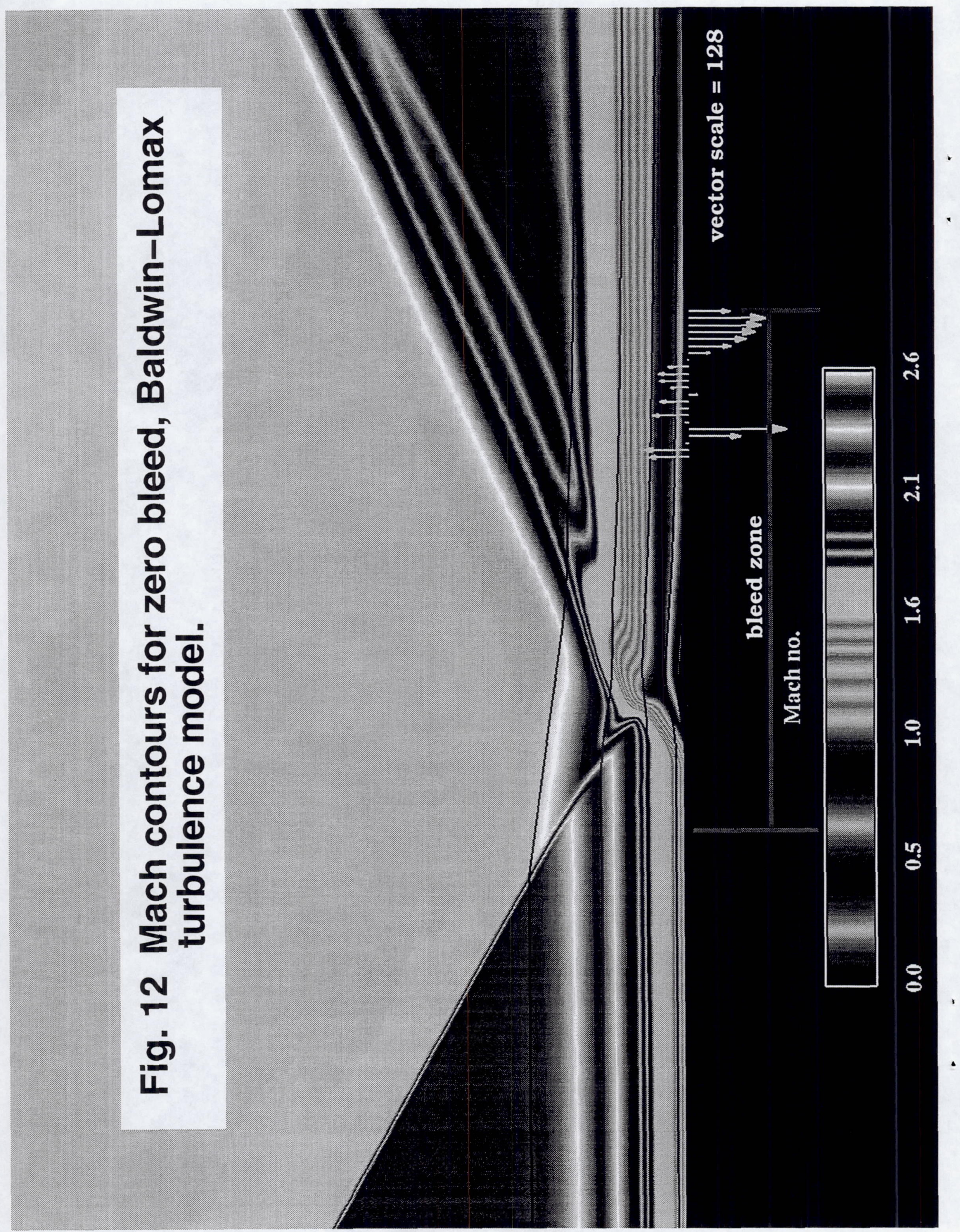



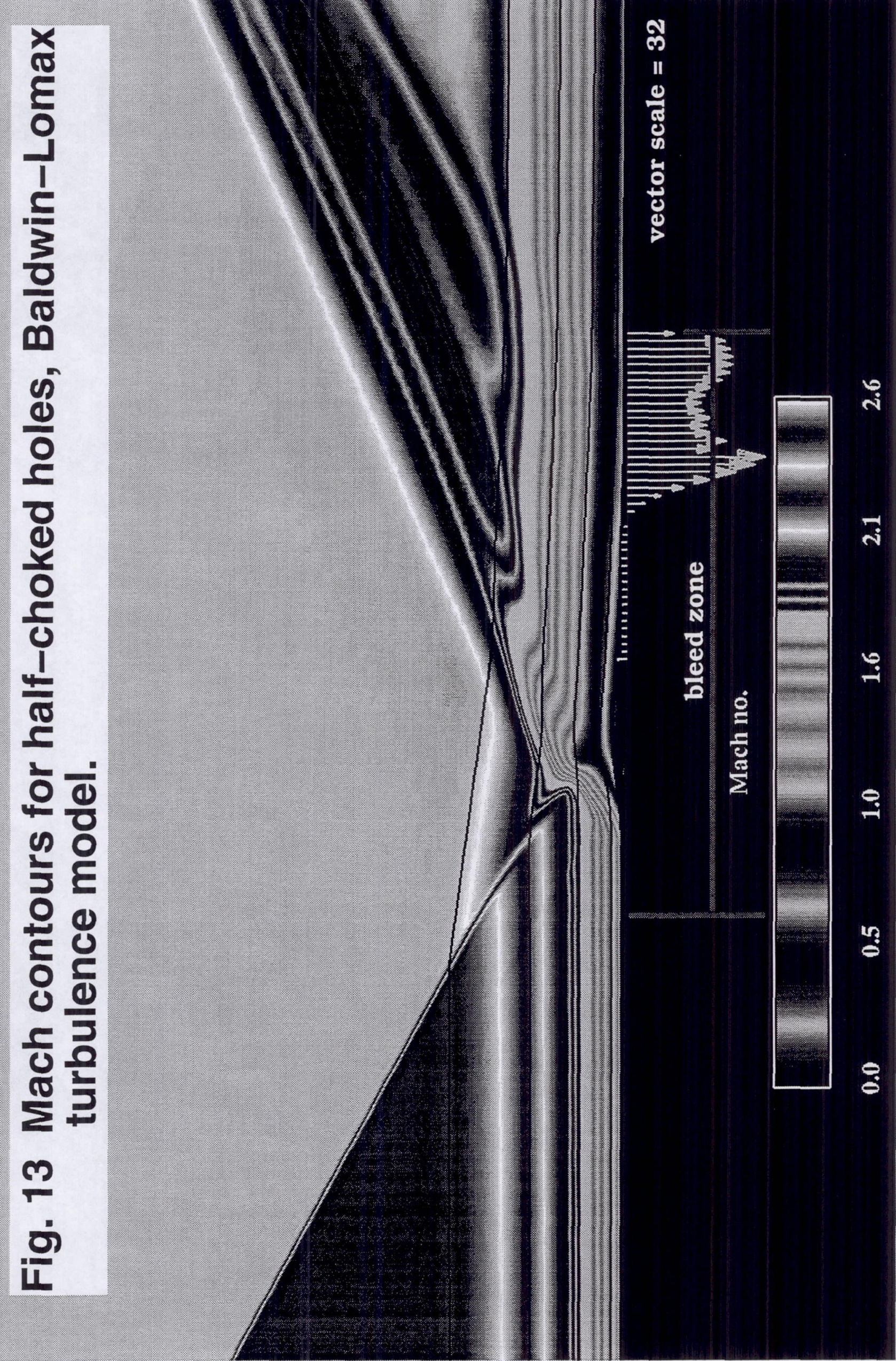


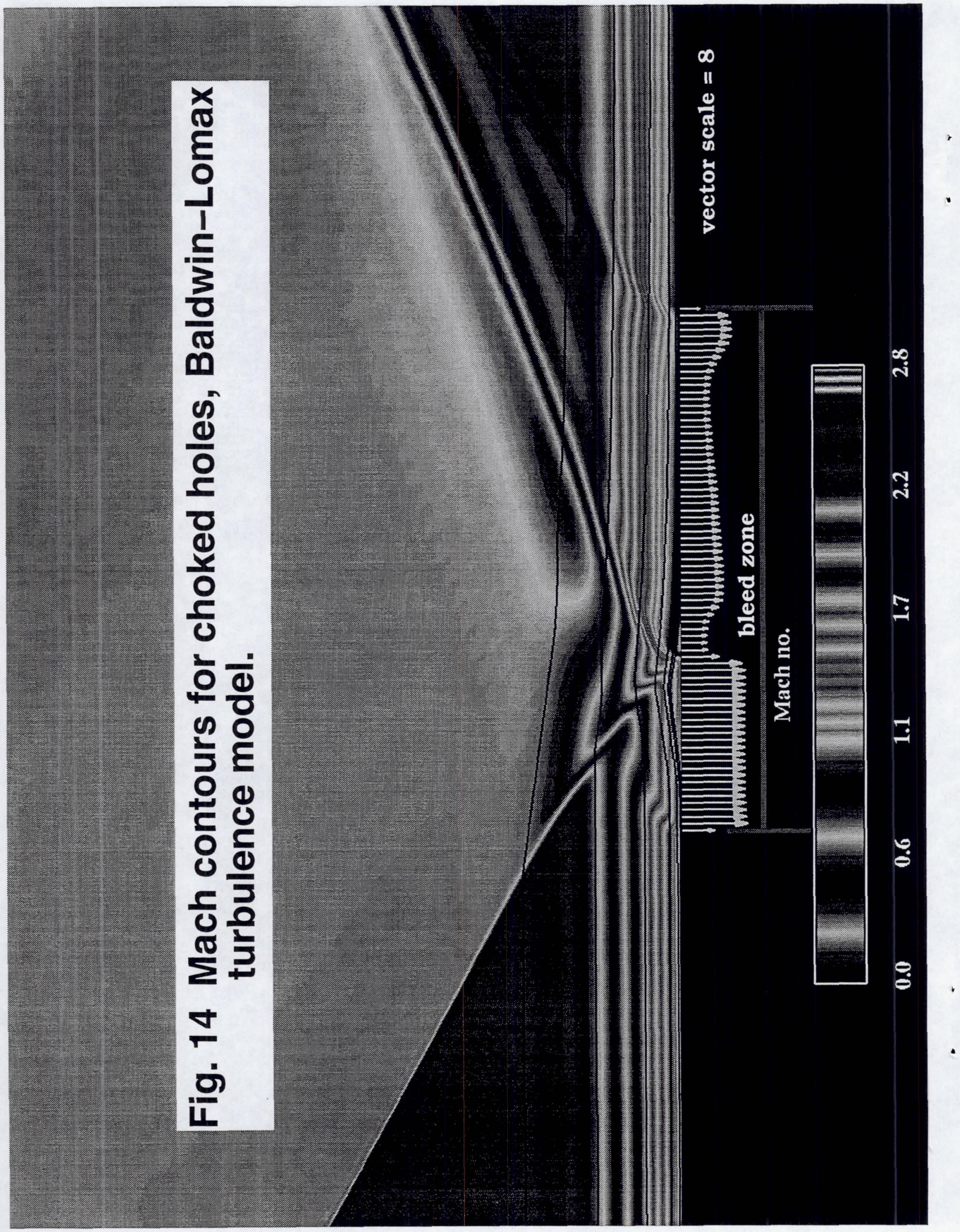


Public reporting burden for this collection of information is estimated to average 1 hour per response, including the time for reviewing instructions, searching existing data sources, gathering and maintaining the data needed, and completing and reviewing the collection of information. Send comments regarding this burden estimate or any other aspect of this collection of information, including suggestions for reducing this burden, to Washington Headquarters Services, Directorate for Information Operations and Reports, 1215 Jefferson Davis Highway, Suite 1204, Arlington, VA 22202-4302, and to the Office of Management and Budget, Paperwork Reduction Project (0704-0188), Washington, DC 20503.

\begin{tabular}{|l|l|r|}
\hline 1. AGENCY USE ONLY (Leave blank) & $\begin{array}{c}\text { 2. REPORT DATE } \\
\text { August } 1995\end{array}$ & $\begin{array}{r}\text { 3. REPORT TYPE AND DATES COVERED } \\
\text { Final Contractor Report }\end{array}$
\end{tabular}

4. TITLE AND SUBTITLE

5. FUNDING NUMBERS

Numerical Simulation of Supersonic Flow Using a New Analytical Bleed

Boundary Condition

WU-505-62-20

C-NAS3-27186

\author{
6. AUTHOR(S)
G.J. Harloff and G.E. Smith \\ 6. AUTHOR(S)
G.J. Harloff and G.E. Smith
}

7. PERFORMING ORGANIZATION NAME(S) AND ADDRESS(ES)

NYMA Inc.

2001 Aerospace Parkway

Brook Park, Ohio 44142

8. PERFORMING ORGANIZATION
REPORT NUMBER

E-9807

9. SPONSORING/MONITORING AGENCY NAME(S) AND ADDRESS(ES)

National Aeronautics and Space Administration

Lewis Research Center

Cleveland, Ohio 44135-3191

10. SPONSORING/MONITORING

AGENCY REPORT NUMBER

NASA CR-198368

11. SUPPLEMENTARY NOTES

Prepared for the 31st Joint Propulsion Conference and Exhibit, cosponsored by AIAA, ASME, SAE and ASEE, San

Diego, California, July 10-12, 1995. Project manager, Thomas J. Biesiadny, Propulsion Systems Division, NASA Lewis

Research Center, organization code 2780 (216) 433-3967.

12a. DISTRIBUTIONAVAILABILITY STATEMENT

12b. DISTRIBUTION CODE

Unclassified - Unlimited

Subject Category 07

This publication is available from the NASA Center for Aerospace Information, (301) 621-0390.

13. ABSTRACT (Maximum 200 words)

A new analytical bleed boundary condition is used to compute flowfields for a strong oblique shock wave/boundary layer interaction with a baseline and three bleed rates at a freestream Mach number of 2.47 with an 8 deg shock generator. The computational results are compared to experimental Pitot pressure profiles and wall static pressures through the interaction region. An algebraic turbulence model is employed for the bleed and baseline cases, and a one equation model is also used for the baseline case where the boundary layer is separated.

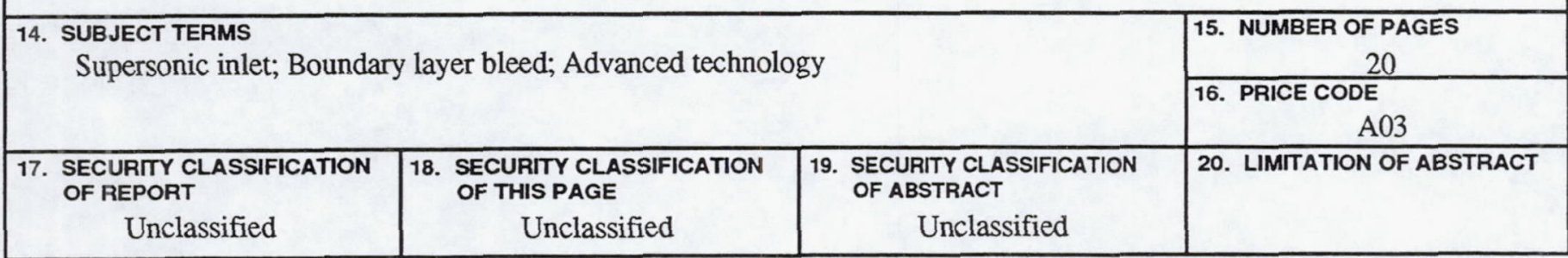

